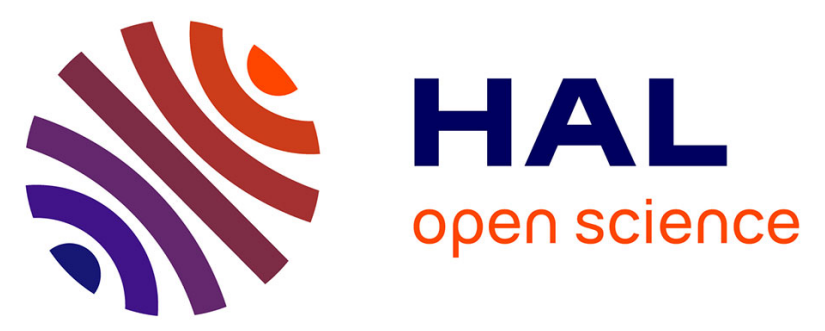

\title{
Semi-Reduction of Internal Alkynes with Prototypical Subnanometric Metal Surfaces: Bridging Homogeneous and Heterogeneous Catalysis with Trinuclear All-Metal Aromatics
}

Anna Monfredini, Veronica Santacroce, Luciano Marchiò, Raimondo Maggi, Franca Bigi, Giovanni Maestri, Max Malacria

\section{To cite this version:}

Anna Monfredini, Veronica Santacroce, Luciano Marchiò, Raimondo Maggi, Franca Bigi, et al.. SemiReduction of Internal Alkynes with Prototypical Subnanometric Metal Surfaces: Bridging Homogeneous and Heterogeneous Catalysis with Trinuclear All-Metal Aromatics. ACS Sustainable Chemistry \& Engineering, 2017, 5 (9), pp.8205-8212. 10.1021/acssuschemeng.7b01847 . hal-01590941

\section{HAL Id: hal-01590941 \\ https://hal.sorbonne-universite.fr/hal-01590941}

Submitted on 20 Sep 2017

HAL is a multi-disciplinary open access archive for the deposit and dissemination of scientific research documents, whether they are published or not. The documents may come from teaching and research institutions in France or abroad, or from public or private research centers.
L'archive ouverte pluridisciplinaire HAL, est destinée au dépôt et à la diffusion de documents scientifiques de niveau recherche, publiés ou non, émanant des établissements d'enseignement et de recherche français ou étrangers, des laboratoires publics ou privés. 


\section{Semi-Reduction of Internal Alkynes with}

\section{Prototypical sub-Nano metric Metal Surfaces:}

\section{Bridging Homogeneous and Heterogeneous}

\section{Catalysis with Trinuclear All-Metal Aromatics}

Anna Monfredini, ${ }^{a \neq}$ Veronica Santacroce, ${ }^{a \dagger}$ Luciano Marchiò, ${ }^{a}$ Raimondo Maggi, ${ }^{a}$ Franca Bigi, $^{a, d}$ Giovanni Maestri ${ }^{* a}$ and Max Malacria ${ }^{b, c}$

a Dipartimento SCVSA, Università di Parma; 17/A Parco Area delle Scienze, 43124 Parma (Italy); giovanni.maestri@unipr.it

b ICSN CNRS (UPR2301); 1 Av. de la Terrasse, Bat. 27, 91198 Gif s/Yvette (France); max.malacria@,cnrs.fr

c UPMC Sorbonne Université, IPCM (UMR CNRS 8232); 4 place Jussieu, C. 229, 75005 Paris (France);

d IMEM-CNR, 37/A Parco Area delle Scienze, 43124 Parma.

Catalysis, Alkynes, Transfer Hydrogenation, Palladium, Aromaticity. 
ABSTRACT: Suitably delocalized metal-metal bonds can stabilize a particular class of discrete trinuclear complexes that are the transition-metal counterparts of carbon-based aromatics. This chemical stability has pivoted the development of an advantageous catalytic method for the semi-reduction of internal alkynes under transfer hydrogenation condition. The reaction does not require any additional solvent and a simple work-up delivers pure products. This combines with broad functional group tolerance, complete cis-selectivity and catalytic charges down to $100 \mathrm{ppm}$ on multi-gram scale.

\section{INTRODUCTION}

All-metal aromatics are highly symmetric cyclic molecules that involve metal atoms in their cores and present delocalized molecular orbitals as regular aromatics. ${ }^{1,2}$ Accordingly, this can represent a strategy to stabilize particular oligometallic species of discrete nuclearity, which in turn could potentially be of high interest for catalysis. ${ }^{3}$ Depending on the coordination properties and formal oxidation states of their constituents, a metal-aromatic behavior has been observed in trinuclear complexes that have differently charged cores. ${ }^{4-7}$ All these complexes are accompanied by the presence of a precise number of electrons and holes that are evenly delocalized in the prototypical metal surface represented by their kernel. Unfortunately, experimental studies on the promising opportunities ${ }^{8}$ of these fascinating molecules are often restricted by synthetic limitations. ${ }^{9}$ Wondering to explore this domain, we recently developed a simple synthetic route to access in one-pot from commercial reagents a family of $\mathrm{M}_{3}{ }^{+}$complexes incorporating palladium or platinum nuclei ${ }^{10}$ upon observation of the metal aromatic character of $\mathrm{Pd}_{3}{ }^{+}$ complexes $^{11}$ laboriously assembled from acyl-isothioureas. ${ }^{12}$ This greatly simplified route enabled to elicit their promising activity and selectivity in the semi-reduction of internal alkynes 
to $c i s$-alkenes under transfer hydrogenation conditions. ${ }^{13}$ These reactions have vast synthetic interest and allow to avoid the use of explosive dihydrogen, as witnessed by the variety of approaches developed in recent years. ${ }^{14-17}$ Most research on homogeneous methods to afford cisalkenes involves the use of mononuclear Palladium complexes. State-of-the-art systems can indeed attain complete chemo and stereo control ${ }^{18-25}$ but their activity comes with an inherently low chemical stability, which often impose $1 \mathrm{~mol} \%$ as the lower bound for catalytic charge. On the other hand, several elegant heterogeneous materials can trigger this reaction too, although this often comes at the cost of issues with catalyst preparation to minimize undesired overreduction of the starting alkyne to alkane. ${ }^{26-30}$

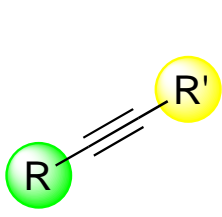

1a-j
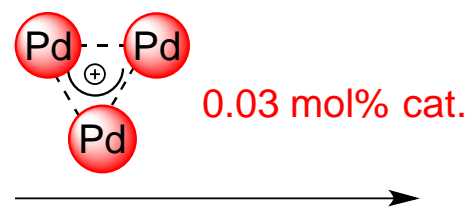

5 equiv. $\mathrm{HCO}_{2}{\mathrm{H} / \mathrm{NEt}_{3}}$

$\mathrm{N}_{2}, 80^{\circ} \mathrm{C}$

$0.09 \mathrm{~mol} \%$ of $\mathrm{P}\left(\mathrm{C}_{7} \mathrm{H}_{7}\right)_{3}$

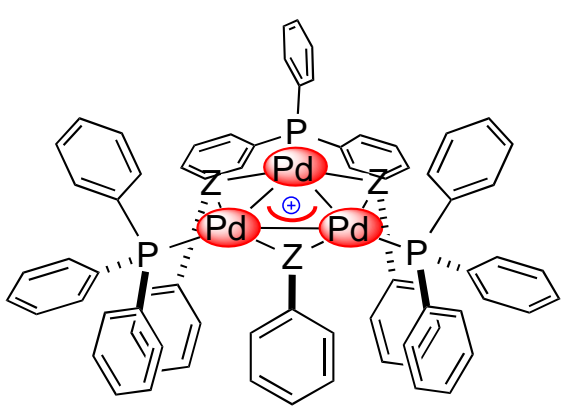<smiles>C=CC</smiles>

2aj, $87-100 \%$

$\checkmark$ simple

$\checkmark$ safe

$\checkmark$ no organics

$\checkmark$ multi-gram
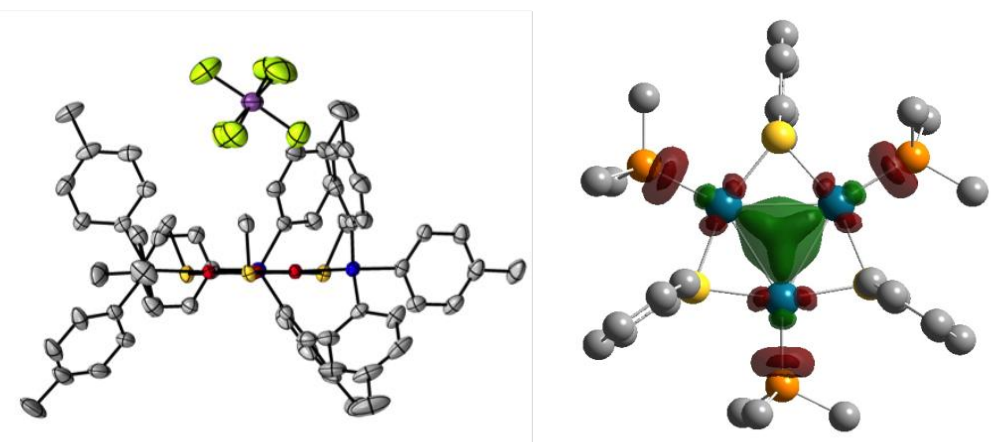
Scheme 1. Catalytic application of metal-aromatic $\mathrm{Pd}_{3}{ }^{+}$complexes for semi-reduction of internal alkynes (top); the X-ray structure of these complexes and their delocalized HOMO (bottom).

We report herein a simple catalytic method for the cis-selective semi-reduction of internal alkynes using triethylammonium formate as reductant (Scheme 1). Taking advantage of our studies on the mechanism of formation of all-metal aromatic $\mathrm{Pd}_{3}{ }^{+}$complexes, ${ }^{31}$ we were able to develop an optimized catalyst that merges chemical stability for up to ten thousand turnovers with surgical cis-alkene selectivity. We exploited these complexes to perform reactions without any additional organics. This combines with a simple work-up procedure to recover almost quantitatively desired products minimizing formation of wastes and catalyst consumption. Taken together with further mechanistic probes, these results highlight the potential of tailor-made stable metal-metal bonds as original strategy to develop greener and more sustainable alternatives for synthesis involving transition-metal based catalysts.

\section{EXPERIMENTAL DETAILS}

Reagents were purchased from commercial sources and used as received. Liquids were degassed by bubbling $\mathrm{N}_{2}$ for at least 20 minutes prior to use. Reactions and filtrations were carried out under $\mathrm{N}_{2}$ using standard Schlenk technique. Trinuclear complexes were prepared in one step from commercial reagents. $\operatorname{Pd}(\mathrm{dba})_{2} \quad(115 \mathrm{mg}, \quad 0.2 \mathrm{mmol}, \quad 1.0 \quad$ equiv. $), \quad 3-$ (diphenylphosphino)benzenesulfonic acid sodium salt $(24 \mathrm{mg}, 0.066 \mathrm{mmol}, 0.33$ equiv.) and tri(p-tolyl)phosphine (40 mg, $0.132 \mathrm{mmol}, 0.66$ equiv.) were sequentially added to a $50 \mathrm{~mL}$ Schlenk, which then underwent at least three vacuum $/ \mathrm{N}_{2}$ cycles. $20 \mathrm{~mL}$ of freshly degassed $\mathrm{CHCl}_{3}$ and dimethyl disulfide ( $9 \mu \mathrm{L}, 0.1 \mathrm{mmol}, 0.5$ equiv.) were sequentially syringed under $\mathrm{N}_{2}$ and the mixture was stirred at room temperature for 3 hours. Traces of black metals were removed via Schlenk filtration through a celite pad and volatiles were removed under vacuum. The solid residue was purified by $\mathrm{CHCl}_{3} /$ hexane washings $(1 / 60 \mathrm{v} / \mathrm{v}, 6 \times 30 \mathrm{~mL})$, affording the 
pure cluster as an orange solid (71 mg, 76\%). For catalytic semi-reductions, the trinuclear complex (2.0 mg, $0.0014 \mathrm{mmol}, 0.03 \mathrm{~mol} \%)$ and tri(p-tolylphosphine) (1.3 mg, $0.0042 \mathrm{mmol}$, $0.09 \mathrm{~mol} \%$ ) were introduced in a Schlenk, which then underwent at least three vacuum/ $\mathrm{N}_{2}$ cycles. Freshly degassed triethylamine $(3.3 \mathrm{~mL}, 23.6 \mathrm{mmol}, 5$ equiv. $)$ and formic acid $(0.9 \mathrm{~mL}$, $23.6 \mathrm{mmol}, 5$ equiv.) were then syringed under $\mathrm{N}_{2}$ and the mixture was stirred for few minutes at room temperature. The desired alkyne $(4.7 \mathrm{mmol}, 1$ equiv.) was then added and the resulting mixture warmed at $80{ }^{\circ} \mathrm{C}$ under stirring. Reagents do not require any anhydrification. Conversion and selectivity were monitored by ${ }^{1} \mathrm{H}$ NMR. Upon alkyne consumption, the crude mixture was adsorbed over a short pad of silica and washed with the minimum amount of solvent to recover pure cis-alkenes. CCDC 1542232 and 1542233 contain the supplementary crystallographic data for complexes II and III respectively.

\section{RESULTS AND DISCUSSION}

During our preliminary studies, ${ }^{31}$ we noticed that the solvent played a role in the reaction leading to the desired complex. A better understanding of these phenomena could prove determinant to achieve a clear picture at the molecular level on factors governing the assembly of small metal surfaces and higher nuclearity aggregates, such as small nanoclusters. We performed additional experiments to gain insights on the mechanism of formation of $\mathrm{Pd}_{3}{ }^{+}$complexes, seeking to understand clues that would be pivotal to future incorporation of different nuclei and organic fragments.

Addition of a two-fold excess of phosphine to our standard method for the synthesis of $\operatorname{Pd}_{3}{ }^{+}$ clusters inhibited their formation. In this case it has been possible to isolate and characterize both a mono- and dimeric Pd(II) complexes that could give insights on intermediates of the reaction leading to $\mathrm{Pd}_{3}{ }^{+}$clusters (Figure 1). In $\left[\mathrm{Pd}\left(\mathrm{PPh}_{3}\right)_{2}(\mathrm{PhS}) \mathrm{Cl}\right]\left[\mathrm{Pd}\left(\mathrm{PPh}_{3}\right)_{2} \mathrm{Cl}_{2}\right]$ (II) the asymmetric unit comprises two co-crystallized square planar $\mathrm{Pd}(\mathrm{II})$ complexes, namely $\left[\mathrm{Pd}\left(\mathrm{PPh}_{3}\right)_{2}(\mathrm{PhS}) \mathrm{Cl}\right]$ and $\left[\mathrm{Pd}\left(\mathrm{PPh}_{3}\right)_{2} \mathrm{Cl}_{2}\right]$, (Figure 1, top). In both systems, the phosphorous atoms are in trans positions. In 
one complex molecule, a thiolate group is in trans to the chloride anion, whereas the second complex is more symmetric since two chloride anions complete the first metal coordination sphere (selected bond distances and angles in SI). The related dimer $\left[\mathrm{Pd}_{2}\left(\mathrm{PPh}_{3}\right)_{2}(\mathrm{PhS}) \mathrm{Cl}_{3}\right] \cdot \mathrm{CHCl}_{3}$ (III) exhibits a symmetric dinuclear structure (Figure 1, bottom), in which the Pd atoms show a square planar geometry with a terminal chloride anion a terminal $\mathrm{PPh}_{3}$ group, a bridging thiolate, and a bridging chloride anion. The $\mathrm{Pd}-\mathrm{Cl}_{\text {bridge }}$ bond distance are approximately $0.1 \AA$ longer than the $\mathrm{Pd}-\mathrm{Cl}_{\text {terminal }}$ ones. The molecular structure is analogous to similar dinuclear systems with bridging thiolates and chloride anions. ${ }^{32-34}$ Nevertheless, in the present case, the assembly involving the metal coordination is planar, at variance with the structure reported in the literature where the two coordination planes are not co-planar. Both complexes represent the proof that the chlorinated solvent is actually a reagent, confirming the preliminary hypothesis that the oxidation of $\operatorname{Pd}(0)$ likely occurs via single electron transfers involving both the disulphide and a chlorinated solvent with suitable C-H BDE. ${ }^{35,36}$ 


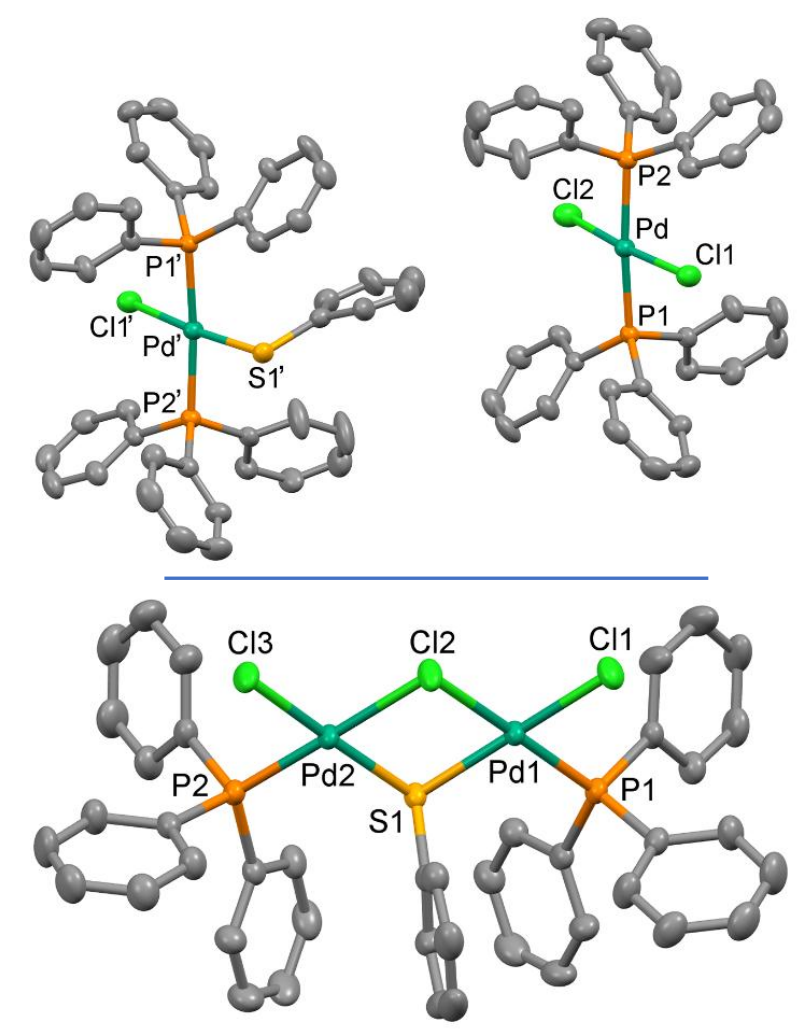

Figure 1. Molecular structure of $\left[\mathrm{Pd}\left(\mathrm{PPh}_{3}\right)_{2}(\mathrm{PhS}) \mathrm{Cl}\right]\left[\mathrm{Pd}\left(\mathrm{PPh}_{3}\right)_{2} \mathrm{Cl}_{2}\right]$ II (top) and of $\left[\mathrm{Pd}_{2}\left(\mathrm{PPh}_{3}\right)_{2}(\mathrm{PhS}) \mathrm{Cl}_{3}\right] \cdot \mathrm{CHCl}_{3}$ III (bottom) with thermal ellipsoids depicted at the $30 \%$ probability level. The $\mathrm{CHCl}_{3}$ molecule and hydrogen atoms were removed for clarity.

We wondered whether the delocalized three-centers-two-electrons bond that is peculiar of allmetal aromatic $\mathrm{Pd}_{3}^{+}$could result from the formal addition of a $\mathrm{Pd}(0)$ fragment onto a coordinatively unsatured $\mathrm{Pd}(\mathrm{II})$ dimer. This would represent a strategy to assemble trinuclear allmetal aromatics complementary to those reported in the literature, which rely on the addition of an oxidized mononuclear complex (such as $\mathrm{Au}(\mathrm{I})$ or $\mathrm{Zn}$ (II) fragments) on a reduced metal dimer that formally provides the two electrons to the metal-aromatic complex (either $\mathrm{Au}(0)$ or $\mathrm{Zn}(\mathrm{I})$ respectively). ${ }^{5,6}$ In order to check if dimeric Pd(II) complex $\mathbf{I V}^{37}$ represents an intermediate in the reaction leading to $\mathrm{Pd}_{3}{ }^{+}$species, we mixed it with 1 equiv. of $\mathrm{Pd}(\mathrm{dba})_{2}$ in a non-chlorinated 
redox-neutral solvent. ${ }^{31}$ Addition of 1 equiv. of triphenylphosphine, sodium thiolate and silver salt in benzene at RT enable complete conversion of the dimer within 30 minutes, as followed via multinuclear NMR analyeses. Figure 2 shows the ${ }^{31} \mathrm{P}$ spectra of this reaction. The reagent (blue line) reacts swiftly and the diagnostic broad peak of trinuclear complex I becomes the main species already after 10 minutes (green line). At the end of the reaction a single resonance remains, witnessing the selectivity of the process (red line). ${ }^{1} \mathrm{H}$ NMR confirmed this trend (spectra in SI).
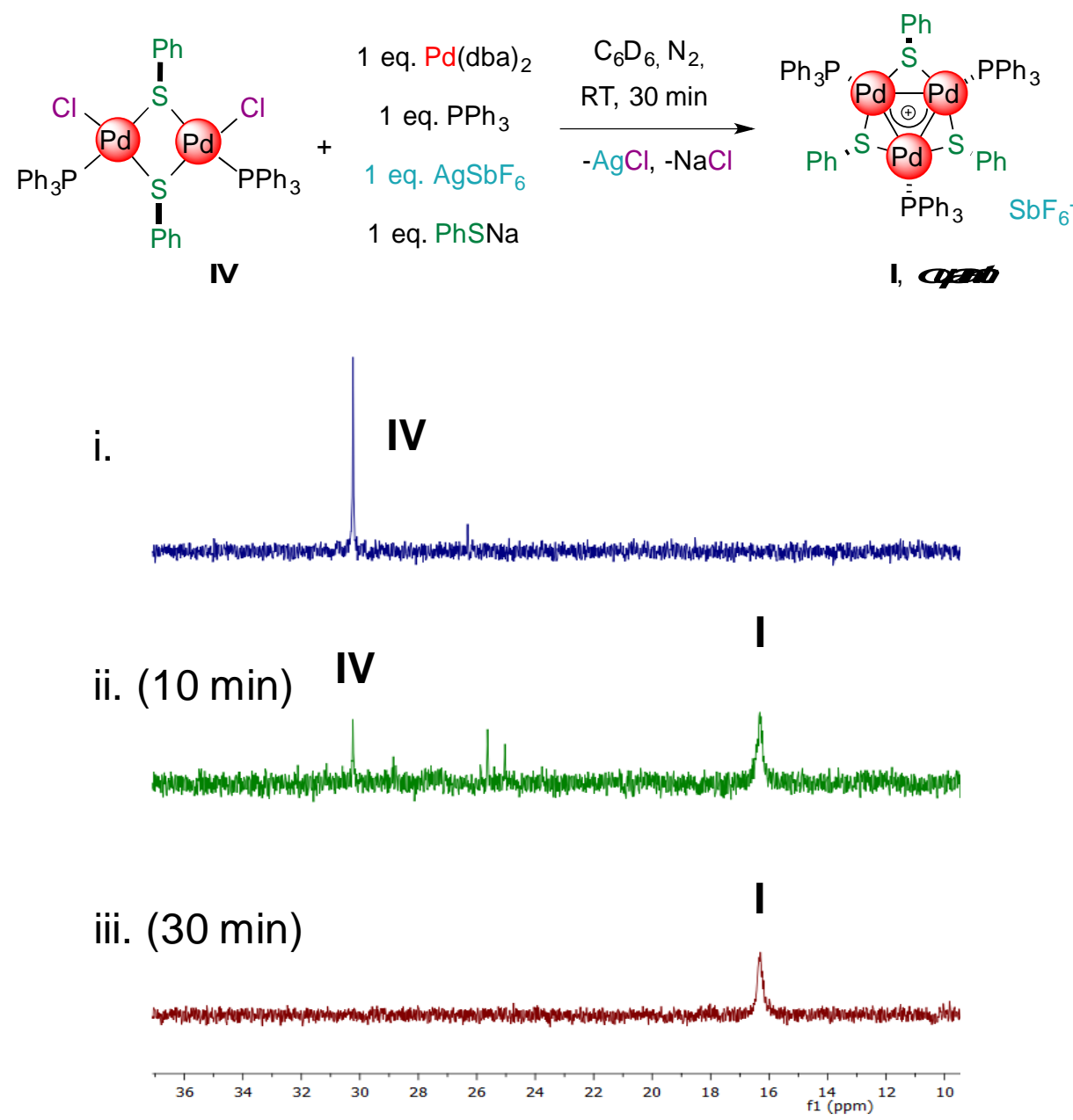

Figure 2. Formation of metal-aromatic $\mathrm{Pd}_{3}{ }^{+}$complex I from a $\mathrm{Pd}(\mathrm{II})$ dimer and $\mathrm{Pd}(0)$. 
This result shows that trinuclear all-metal aromatics can be accessed through addition on oxidized dimers of mononuclear fragments that can formally undergo two-electrons oxidation to access trinuclear complexes with delocalized three-center-two-electrons bonds. This is complementary to existing literature ${ }^{4-7}$ and might thus represent a valuable addition for future developments. The assembly of novel discrete clusters with aromatic metal-metal bonds could indeed extend the panel of readily available prototypical metal surfaces.

These platforms can show interest catalytic applications, as witnessed by the selectivity towards cis-alkenes displayed by highly symmetric $\mathrm{Pd}_{3}{ }^{+}$complex $\mathbf{I}$ in the semi-reduction of internal alkynes under transfer-hydrogenation conditions, even despite large molar excess of hydrogen donor. Among a variety of substrates, reactions never displayed the least trace of over-reduction, namely alkane formation. ${ }^{13}$ Intrigued by this unique selectivity, we developed a second generation catalytic system that works without additional solvents, enabling in turn to minimize both formation of wastes and the catalytic charge. These features are unique among mononuclear homogeneous catalysts, and proved possible exploiting zwitterionic $\mathrm{Pd}_{3}{ }^{+}$complex $\mathbf{A} .{ }^{31}$ Complex A-C were thus synthesized (Scheme 2) and used as tool to further study the properties of these clusters as catalyst for the semi-reduction of internal alkynes to cis-alkenes.

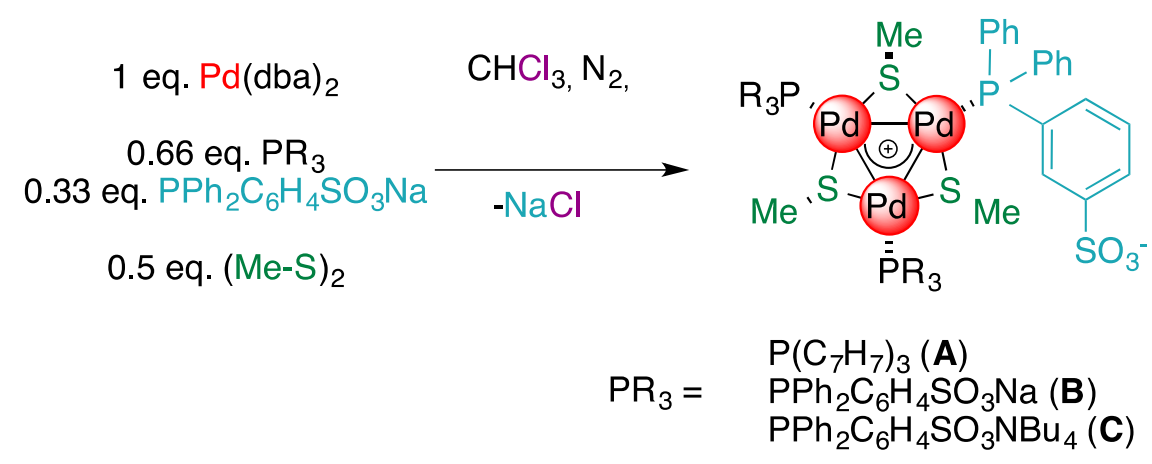

Scheme 2. Synthesis of catalysts used in this study. 
Under optimized conditions, phenylpropyne can be converted almost quantitatively to cis-alkene 2a in few hours consuming as low as $0.03 \mathrm{~mol} \%$ of catalyst in combination with $0.09 \mathrm{~mol} \%$ of an additional phosphinic ligands. This proved determinant to minimize the odds of complex decomposition when the substrate concentration faded, as determined through UV-Vis titrations. To check the generality of this trend, we repeated our model reactions with various combination of complexes A-C and additional ligands. Results are summarized in Table 1.

Table1. Screening of catalyst for semi-reduction of phenylproyne.
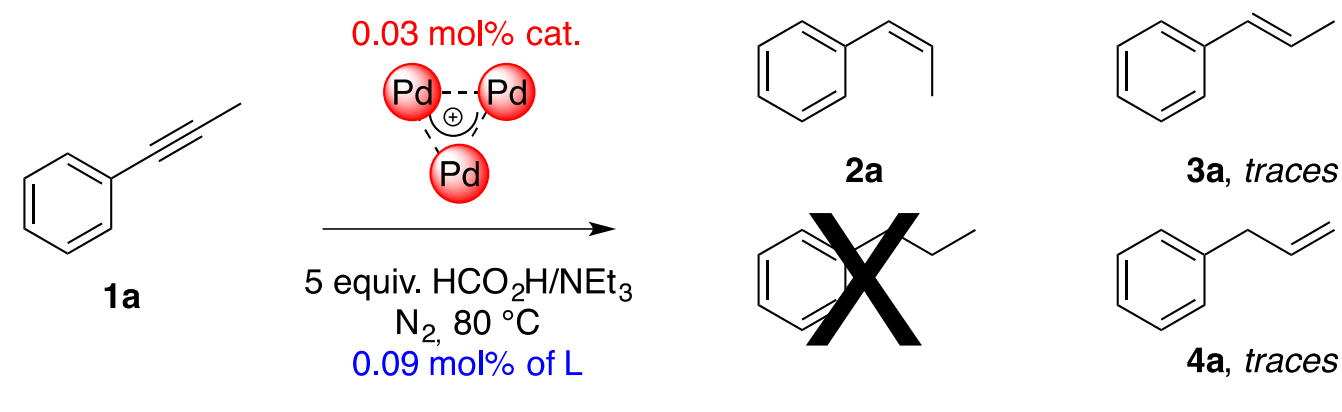

3a, traces

\begin{tabular}{cccccc}
\hline Entry & $\begin{array}{c}\mathrm{Pd} \\
\text { complex }\end{array}$ & $\mathrm{L}$ & $\mathrm{t}(\mathrm{h})^{\mathrm{a}}$ & $\begin{array}{c}\text { Conv. } \\
\mathbf{1 a}(\%)\end{array}$ & $\begin{array}{c}\text { Sel. } \\
\mathbf{2 a}(\%)^{\mathrm{b}}\end{array}$ \\
\hline 1 & $\mathrm{Pd}_{3}^{+} \mathbf{A}$ & $\mathrm{P}\left(4-\mathrm{Me}-\mathrm{C}_{6} \mathrm{H}_{4}\right)_{3}$ & 6 & quant. & 98 \\
2 & $\mathrm{Pd}_{3}{ }^{+} \mathbf{A}$ & $\mathrm{C}_{6} \mathrm{H}_{5}-\mathrm{SNa}_{\mathrm{Na}}$ & 5 & 36 & 100 \\
3 & $\mathrm{Pd}_{3}{ }^{+} \mathbf{B}$ & $\mathrm{P}\left(4-\mathrm{Me}-\mathrm{C}_{6} \mathrm{H}_{4}\right)_{3}$ & 6 & quant. & 94 \\
4 & $\mathrm{Pd}_{3}{ }^{+} \mathbf{B}$ & $\mathrm{P}(\mathrm{Ph})_{2} \mathrm{C}_{6} \mathrm{H}_{4} \mathrm{SO}_{3} \mathrm{Na}$ & 6 & 94 & 97 \\
5 & $\mathrm{Pd}_{3}{ }^{+} \mathbf{C}$ & $\mathrm{P}\left(4-\mathrm{Me}-\mathrm{C}_{6} \mathrm{H}_{4}\right)_{3}$ & 8 & 96 & 96 \\
6 & $\mathrm{Pd}_{\mathbf{I I}}$ & $\mathrm{P}\left(4-\mathrm{Me}-\mathrm{C}_{6} \mathrm{H}_{4}\right)_{3}$ & 8 & 72 & 92 \\
7 & $\mathrm{Pd}_{2} \mathbf{I I I}$ & $\mathrm{P}\left(4-\mathrm{Me}-\mathrm{C}_{6} \mathrm{H}_{4}\right)_{3}$ & 8 & 24 & 98 \\
8 & $\mathrm{Pd}_{2} \mathbf{I V}$ & $\mathrm{P}\left(4-\mathrm{Me}-\mathrm{C}_{6} \mathrm{H}_{4}\right)_{3}$ & 6 & 45 & 94
\end{tabular}

Reaction conditions: 1a (4.7 mmol, 1 equiv.), $\mathrm{Pd}_{3}{ }^{+}$complex A ( $2 \mathrm{mg}, 0.0003$ equiv.), tri-ptolylphosphine ( $1.3 \mathrm{mg}, 0.0009$ equiv.), $\mathrm{NEt}_{3}$ ( $3.3 \mathrm{~mL}, 5$ equiv.) $\mathrm{HCO}_{2} \mathrm{H}(0.9 \mathrm{~mL}, 5$ equiv.), under $\mathrm{N}_{2}$ at $80{ }^{\circ} \mathrm{C} ;{ }^{a}$ time to reach full conversion; ${ }^{b}$ determined by ${ }^{1} \mathrm{H}$ NMR. 
The combination of complex $\mathbf{A}$ and tritolylphosphine provided the best result (entry 1). The reagent was fully consumed upon warming the mixture for 6 hours, delivering $98 \%$ of cis-alkene 2a. Traces of trans-product 3a and allylbenzene (4a) were barely visible with GC analyses (1\% each). Replacement of the additional phosphine with a thiolate quenched reactivity (entry 2) and conversion remained stuck at $36 \%$ upon the first 5 hours. This result suggest that a phosphine could stabilize the complex in the reducing medium while an excess of thiolate did not have a meaningful effect to this end. On the contrary, the apparent rate of the semi-reduction slows down, suggesting that this species could compete with formate anions. Decoration of the $\operatorname{Pd}_{3}^{+}$ kernel with three anionic phosphines (complex B, entry 3) provided 2a in 94\% yield upon 6 hours, showing therefore a limited erosion of the selectivity. Replacing the added neutral phosphine with the sodium salt of a sulfonated one increased the selectivity to $97 \%$ (entry 4), although conversion ceased at $94 \%$. Wondering whether this might be due to solubility issues, we prepared complex $\mathbf{C}$ in which alkali countercations were replaced by tetrabutylammonium ones. The resulting complex is soluble even in strongly apolar media, but did not provide a further boost of either activity or selectivity (entry 5). We then tested monomeric complex II (entry 6). Under best conditions, alkyne consumption ended upon 8 hours ( $72 \%$ conversion), delivering cis-alkene with $92 \%$ selectivity. Dinuclear complexes III and IV followed suit (entries 7-8). Conversion ceased at $24 \%$ and $45 \%$ respectively. No further changes were observed prolonging warming for 24 additional hours. During these experiments (entries 6-8), black metal colloids started forming from the beginning despite a high concentration of substrate. Selectivity remained high in all cases, suggesting that these heterogeneous aggregates are fairly active at most either for alkyne semireduction or alkene isomerization under these conditions (vide infra). Taken together, these results confirm that zwitterionic $\mathrm{Pd}_{3}{ }^{+}$complexes with 
delocalized metal-metal bonds are efficient catalyst for solvent-free semi-reduction of internal alkynes to $c i s$-alkenes. We thus tested the scope of this reaction (Table 2).

Table 2. Reaction scope

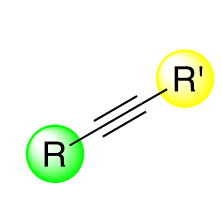

1a-n
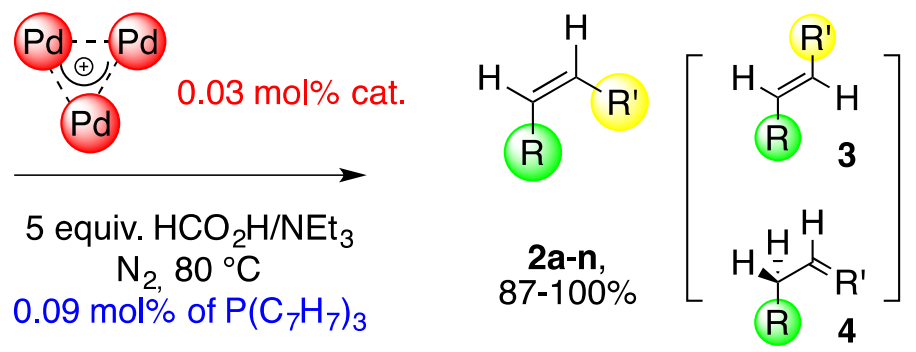

Entry




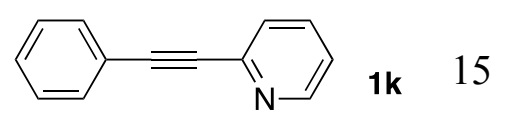

100

95

12

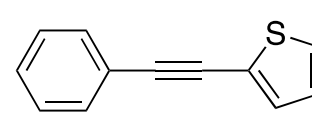

116

100

99

13

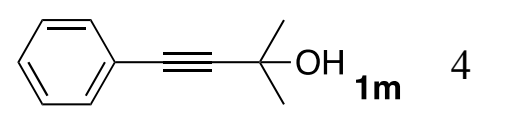

100

99

14

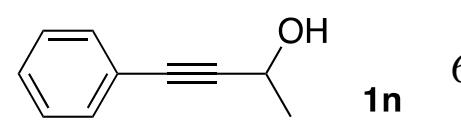

94

$85^{\mathrm{d}}$

Reaction conditions: as Table 1 ; $^{\mathrm{a}}$ time to reach full conversion of $\mathbf{1}$; ${ }^{\mathrm{b}}$ determined by ${ }^{1} \mathrm{H} \mathrm{NMR}$; ${ }^{\mathrm{c}}$ products 2 were purified by filtration on a silica pad eluting with $5 \mathrm{~mL}$ of solvent; ${ }^{\mathrm{d}}$ isolated with traces of trans-olefin 3; ${ }^{\mathrm{e}}$ conversion ceased at 95\%, recovered with residual donor for its volatility; ${ }^{\mathrm{f}}$ conversion ceased at $87 \%{ }^{\mathrm{g}}$ conversion ceased at $95 \%$.

In general, an ample mix of internal alkynes can be converted to the corresponding cis-alkene $\mathbf{2}$ in excellent to quantitative yields. Beside $\mathbf{2 a}$ (entry 1), hindrance close to the triple bond requires longer reaction time to quantitatively convert the alkyne to alkenes $\mathbf{2 - 3 b}$ (entry 2 , in 90/10 ratio upon 15 hours). This represent nonetheless an improvement over first generation cationic complexes, which delivered a 78/21/1 ratio of $\mathbf{2 b - 4 b}$ upon 24 hours. $^{13}$ Various propargylic ethers can be smoothly converted, portraying the tolerance to benzylic substituents (entries 3-4, 93\% and 96\% yields of $\mathbf{2 c}$ and $\mathbf{2 d}$ respectively). Similarly, substitution of butyndiol with various fragments enabled to access cis- diethers $\mathbf{2 e - 2 g}$ quantitatively. Remarkably, the C$\mathrm{Br}$ bonds of $1 \mathrm{~g}$ remain untouched, leaving a valuable handle for further functionalization. All these ethers present propargylic $\mathrm{C}-\mathrm{H}$ bonds that could easily undergo homolytic cleavage. In order to perform reactions with these low catalyst loadings $(0.03 \mathrm{~mol} \%)$ these reagents require purification on silica gel or distillation prior to use. This is no longer required using higher 
loadings instead ( $1 \mathrm{~mol} \%)$, indicating that the purity of reagents can become an important issue to preserve chemical stability over several thousand turnovers. Substituted propiolic acids could be employed (entry $8,100 \%$ ), showing that conjugated carboxylic acids did not hamper the reaction. Diarylacetylenes, including heteroaryl ones followed suit (2i-1, entries 9-12). Both 3and 2-pyridyl fragments afforded exclusively the cis-product. Conversion was stuck at $87 \%$ with the former (entry 10), while the latter delivered $95 \%$ of $2 \mathbf{k}$ upon 15 hours. Thiophene rings are similarly tolerated, as witnessed by the smooth semi-reduction of $\mathbf{1 l}$ that gave quantitatively $\mathbf{2 l}$ in 6 hours. Hindered propargylic alcholos are efficient reagents too (1m-n, entries 13-14). Taken together these results shows that present complex displays chemical stability for at least 3300 turnovers over an ample mix of functionalized substrates, combined with high activity and often complete selectivity.

In all these cases reactions mixtures remain clean solutions without traces of black metal colloids until complete alkyne conversion. This feature is obtained thanks to the addition of the extra phosphine and enables to quench undesired isomerization of $c i s$-alkenes, which was instead partially observed with first generation catalysts ( $1 \mathrm{~mol} \%$ in THF). ${ }^{13}$ The partial decomposition of the latter can be monitored via ESI-MS analyses on samples collected from reaction mixtures at regular intervals, which present a fading ionic concentration of $\mathrm{Pd}_{3}{ }^{+}$complex through time. We reasoned that this partial decomposition might generate palladium species that are the actual isomerization catalyst responsible for the formation of isomerized olefins and which might have different nuclearity. This can be consistent with the observation of $10 \%$ of $\mathbf{3 b}$ (Table 2, entry 2 ) employing the least reactive alkyne of the series. In this case, the prolonged warming has likely caused partial complex decomposition. Addition of a phosphinic ligand (3 equiv. compared to $\mathbf{A}$ ) prevented formation of trans- and isomerized alkenes, delivering $98 \%$ of $2 \mathbf{a}$ upon 4 hours in 
THF. The stability of $\mathbf{A}$ can be proved by UV-Vis analyses on reaction samples collected at regular intervals. The diagnostic bands of complex A, between 350 and $450 \mathrm{~nm},{ }^{31}$ did not change throughout the reaction. This means that the complex is stable under reaction conditions and that its average concentration did not change significantly until $\mathbf{1 a}$ is completely semi-reduced to $\mathbf{2 a}$. On the other hand, the reductive reaction environment can cause partial decomposition through time of complex A. This is clearly witnessed by visible formation of black colloids prolonging warming upon full alkyne conversion. Many palladium species are able to reduce alkynes under transfer-hydrogenation conditions. ${ }^{38-40}$ For comparison, commercial $\mathrm{Pd}(\mathrm{dba})_{2}(1 \mathrm{~mol} \%)$ becomes no longer active upon $24 \mathrm{~h}$ warming, delivering $82 \%$ conversion of $1 \mathrm{a}$ and $13 \%$ alkane. Addition of ligands as phosphines and thiolates in semi-reduction with $\mathrm{Pd}_{3}{ }^{+}$complexes has an impact on the formation of undesired products (Table 1). Addition of 10 equiv. of phosphine compared to A slows the reaction (24 hours) and 2a exclusively forms (98\%). Phosphines and thiolates can become efficient poisons, especially for higher nuclearity aggregates whose surface to volume ratio sinks compared to mononuclear complexes and discrete clusters. Thanks to this, substoichoimetric amounts can already quench reactivity. ${ }^{40}$ Performing the Sheldon hot filtration test by pouring the crude on a short celite pad in a Schlenk filter, did not hamper the model reaction of 1a and conversion of the latter proceeded linearly. Taken together, these results suggest that the catalyst of present reactions is a homogeneous species.

The aromatic metal-metal bond of $\mathbf{A}$ should grant him a relative stabilization in respect to nucleation processes. ${ }^{1-8}$ We cannot rule out that the trinuclear complex can enter equilibria with species of either lower or higher nuclearity. They could actually be the most active palladium particles in reaction mixtures and clear-cut identification of the actual catalyst is often very difficult. $^{38-39}$ 
Figure 3 present the series of ${ }^{1} \mathrm{H}$ NMR spectra collected during the semi-reduction of $\mathbf{1 f}$ (purple line). Beside triethylammonium formate, no other organic except $\mathbf{1 f}$ and $\mathbf{2 f}$ appears throughout the experiment. Copies of ${ }^{1} \mathrm{H}$ NMR spectra clearly present this outcome, comparing samples collected upon 1 (blue line), 2 (green), 3 (yellow) and 5 hours respectively (red). It is worth noting that upon full conversion of alkyne $\mathbf{1 f}$ (violet line), the crude mixture is essentially a pure solution of cis-alkene $\mathbf{2 f}$.

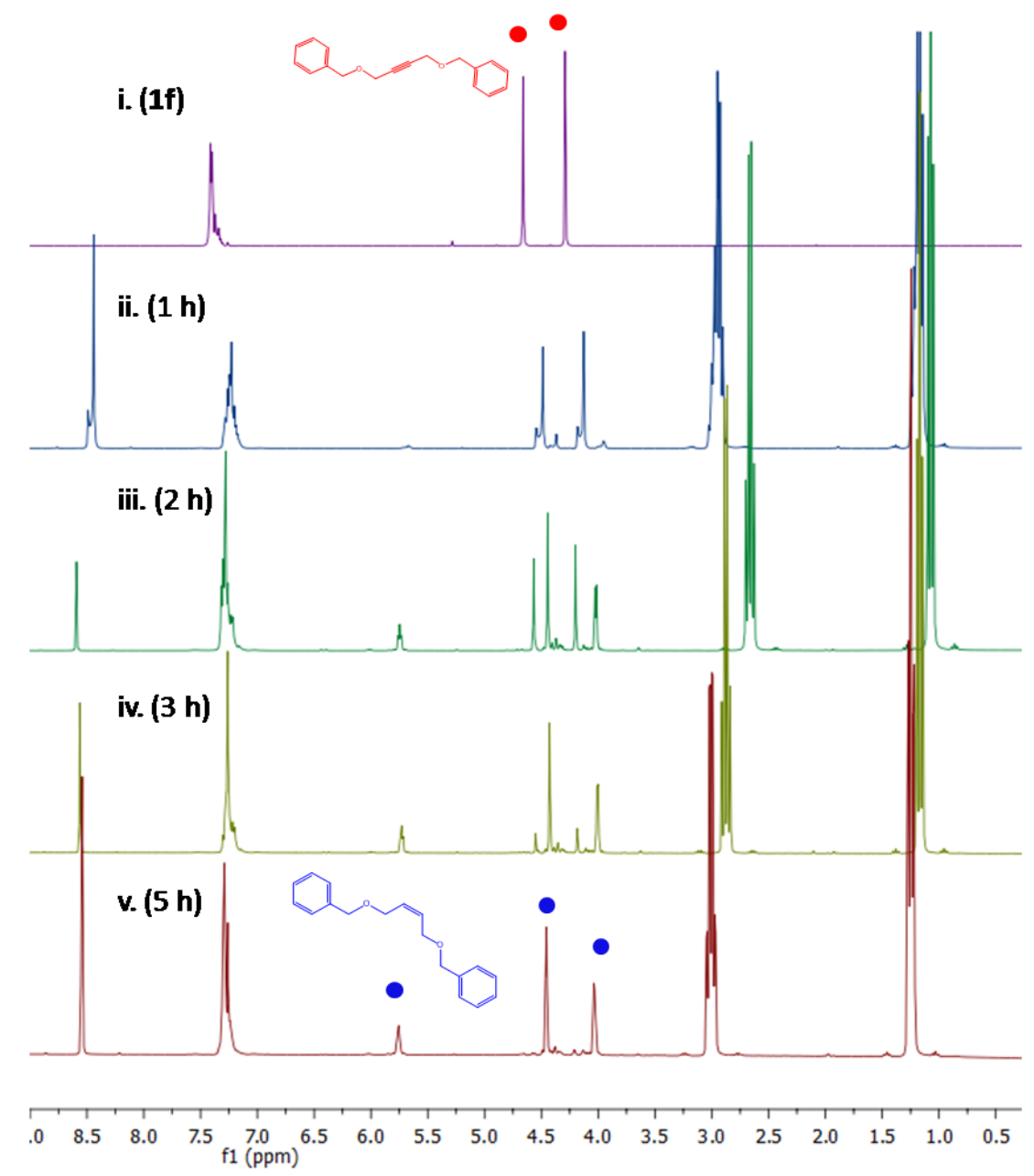

Figure 3. Quantitative conversion of alkyne $\mathbf{1 f}$ to cis-alkene $\mathbf{2 f}$ through time.

These results confirm the hypothesis that $\mathrm{Pd}_{3}{ }^{+}$complexes $\mathbf{A}$ do not catalyze any alkene isomerization. To further check this feature, we performed deuterium labeling experiments. 
Using first generation cationic complexes without addition phosphine ligands, deuterium was non-selectively retrieved on the three non-aromatic carbons of 2a in a roughly $2: 2: 1$ ratio with DCOOD as hydride source. Traces of $\mathbf{3 a}$ and $\mathbf{4 a}$ (3\% and $4 \%$ respectively) behave similarly. In this case, 24 hours were necessary to consume 1a, while the reaction was completed within 10 hours using unlabeled formic acid. This is consistent with a relevant primary kinetic isotopic effect and, in turn, likely caused partial complex decomposition over the longer experiment, which we speculate as the root of both double bond isomerization and H/D scramblings. ${ }^{41}$ Repeating this model reaction with zwitterionic complexes under solvent-free conditions enabled the consumption of 1a within 9 hours (Scheme 3). This combines with a higher selectivity for cis-alkene (2a- $d, 97 \%)$. The trans-alkene 3a no longer forms, and 4a- $d$ is observed in traces (3\%). Regarding deuterium incorporation, an average of two D nuclei for each molecule is observed. In particular, significant incorporation on the terminal carbon of $\mathbf{2 a}$ is observed (18\%). Furthermore, the methylene group of $\mathbf{4 a}$ is almost completely deuterated (84\%). These findings have no precedent ${ }^{18-25}$ among homogeneous Pd-based catalysts and suggest that 1a can isomerize to phenylallene 5a, via sequential 1,3-hydride addition/elimination during the reaction. ${ }^{42-44}$ These results support the hypothesis that $\mathrm{Pd}_{3}{ }^{+}$complexes $\mathbf{A}$ can catalyze both alkyne/allene isomerization and reduction ${ }^{45}$ and neither alkene isomerization nor over-reduction. We could not rule out at present stage that this distribution of olefins $2 \mathbf{a}$ and $4 \mathbf{a}$ stems from hydrogenolysis of a palladium allyl intermediate, which would favor formation of the aryl-conjugated cis-olefin. We repeated deuterium labeling experiments on alkyne 1d, which features a non-conjugated triple bond flanked by a methyl and a methylene substituted by an electron-donating oxygen (lower part of Scheme 3, copies of NMR spectra in SI). Full conversion occurred upon 15 hours, confirming the impact of primary kinetic isotope effect. Products $\mathbf{2 - 4 d}$ were retrieved in a 95:2:3 
ratio. The amount of $\mathrm{D}$ on the terminal methyl of $\mathbf{2 d}$ was $58 \%$, thus even more than the $18 \%$ value observed in 2a. We were unable to quantify deuterium incorporation on 3d. The allylic methylene of isomerized olefin $\mathbf{4 d}$ is fully deuterated. None of $\mathbf{2 - 4 d}$ displayed deuterium incorporation on the ethereal methylene of $\mathbf{1 d}$. This could correlate with an unfavourable hydride 1,3-addition/elimination leading to an allene different from $\mathbf{5 d}$ caused by the presence of the electron-donating ethereal oxygen.

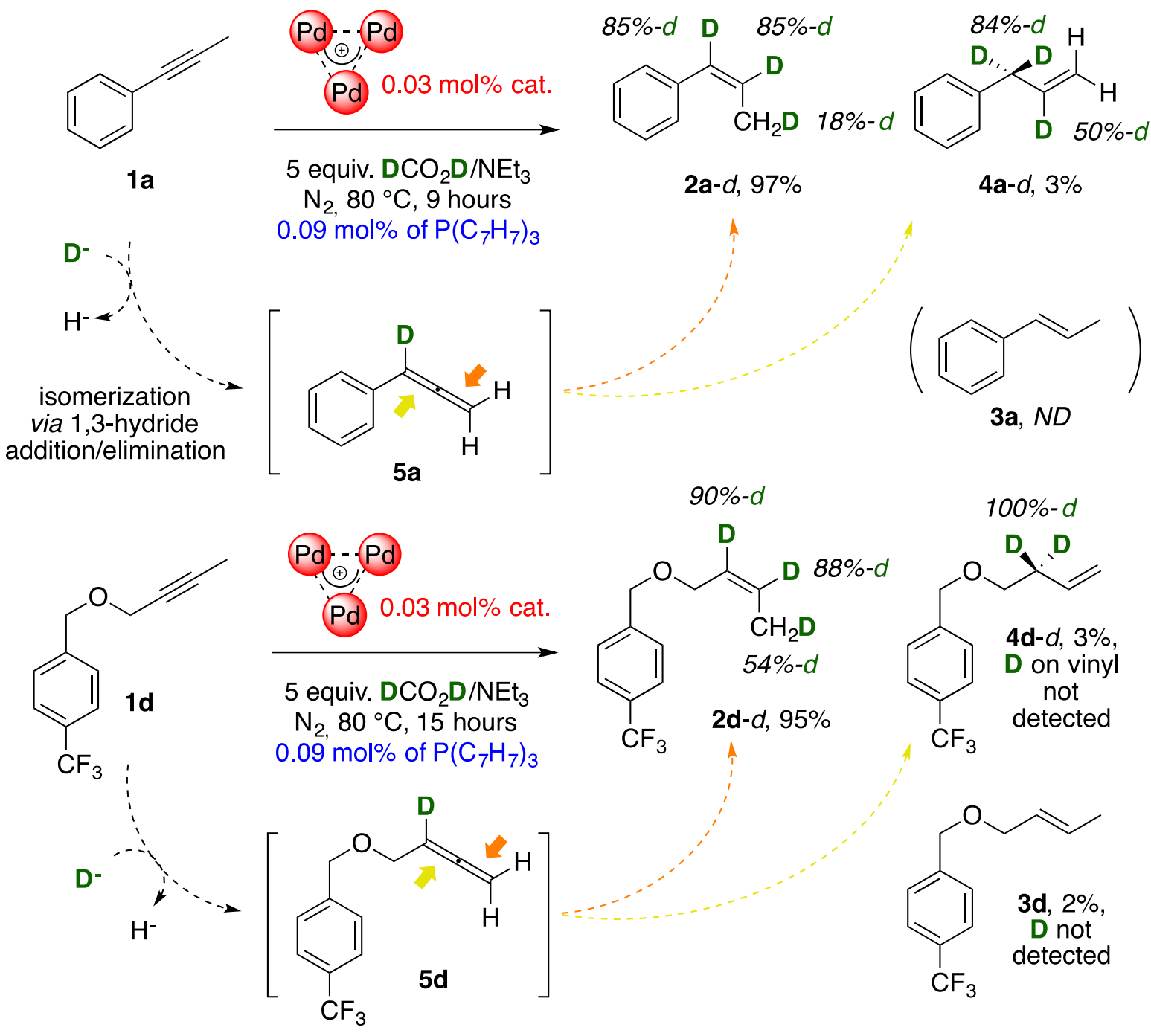

Scheme 3. Deuterium-labelling experiments. 
Isomerization of $\mathbf{1}$ to $\mathbf{5}$ liberates a hydride. This could in principle contribute to catalyst decomposition, possibly altering its nuclearity and eventually leading to visible black metal colloids in the reductive reaction medium. Reasoning that 1,3-hydride addition/elimination on internal alkynes requires a propargylic $\mathrm{C}-\mathrm{H}$ group, we wondered whether it would have been possible to further push reaction conditions using diphenylacetylene $1 \mathbf{i}$ as model.

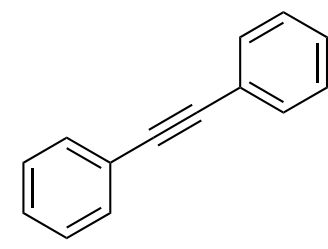

$1 \mathrm{i},(6.24 \mathrm{~g})$

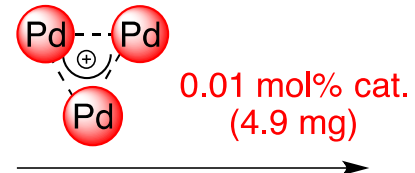

2 equiv. $\mathrm{HCO}_{2} \mathrm{H} \mathrm{NEt}_{3}$ $\mathrm{N}_{2}, 80^{\circ} \mathrm{C}, 6$ hours $0.03 \mathrm{~mol} \%$ of $\mathrm{P}\left(\mathrm{C}_{7} \mathrm{H}_{7}\right)_{3}$<smiles>C=Cc1ccccc1</smiles>

2i, quant. $(6.31 \mathrm{~g})$

$$
\begin{aligned}
& \text { TON }=10 \mathrm{~K} \\
& \text { TOF }=3 \mathrm{~K}\left(h^{-1}\right)
\end{aligned}
$$

Scheme 4. Multi-gram scale synthesis of cis-stilbene (2i) with $0.01 \mathrm{~mol} \%$ of $\mathrm{Pd}_{3}{ }^{+}$catalyst.

Scheme 4 presents the summary of a brief dedicated optimization (further details in SI). It is possible to keep a practical reaction times (6 hours) and complete selectivity for cis-alkene $\mathbf{2 i}$ reducing both the molar excess of hydrogen donor (down to 2 equiv.) and the catalyst amount $(0.01 \mathrm{~mol} \%)$. This minimizes the consumption of chemicals en route to pure product. ${ }^{46-51}$ The reaction can be performed on multigram scale $(6.24 \mathrm{~g}, 35 \mathrm{mmol})$ consuming few milligrams of catalyst and phosphine ( 4.9 and $3.2 \mathrm{mg}$ respectively) and $10.3 \mathrm{~g}$ of hydrogen donor. ${ }^{52}$ Pure $2 \mathbf{i}$ can be quantitatively recovered $(6.31 \mathrm{~g})$ pouring the crude on short silica pad $(4.0 \mathrm{~g})$ and eluting with $12.5 \mathrm{~g}$ of pentane $(20 \mathrm{~mL})$. This clearly highlight the synthetic viability of the method. ${ }^{53}$ Although $\mathrm{Pd}_{3}{ }^{+}$complexes can be purified by flash chromatography on silica gel, ${ }^{10}$ this recovery method is not feasible with present multigram-scale reactions. This approach would also yield a large increase of the amount of wastes. With present simple purification, palladium remains 
mostly adsorbed on the short silica pad. On the other hand, even assuming that it quantitatively contaminates $\mathbf{2 i}$, this would result in a heavy metal content equal to $174 \mathrm{ppm}$ only.

Table 3. Calculated green metrics

\begin{tabular}{llll}
\hline Entry & Yield (\%) & E-factor & PMI \\
\hline This procedure & 100 & 4.24 & 5.24 \\
Furstner procedure $^{19}$ & 82 & 45.8 & 46.8 \\
Elsevier procedure $^{21}$ & 99 & 31.7 & 32.7 \\
Copéret procedure $^{29}$ & 99 & 24.4 & 25.5 \\
Studer procedure $^{30}$ & 99 & 52.9 & 53.9 \\
\hline
\end{tabular}

Table 3 presents a selection of calculated green metrics comparing this procedure with four representative ones, which make use of organic solvents and require work-up or chromatographic purifications. We calculate E-factor and PMI index to quantify a possible benefit coming from the absence of unnecessary organics in our model reaction combined with its simple purification methods. The use of solvents, work-up extractions and/or column chromatography usually results in values above 20 even for most efficient methods, either based on homogeneous catalysts ${ }^{18-25}$ or heterogeneous ones. ${ }^{26-30}$ On the contrary, a meaningful enhancement on viability is found in this case, E-factor and PMI being 4.24 and 5.24 respectively. These results further suggest the promising role of small metal surfaces as tool to devise new sustainable catalytic methods.

\section{CONCLUSIONS}


We reported a study clarifying the mechanism of formation of all-metal aromatic $\mathrm{M}_{3}^{+}$ complexes. This enabled to devise an alternative route for the assembly of these prototypical noble-metal surfaces. These frameworks can be tailored at the molecular level, like most homogeneous catalysts. Similarly, remarkable selectivity is shared too. Internal alkynes can be easily converted under transfer hydrogenation conditions to the corresponding cis-alkenes without any unnecessary organics. This is accompanied by chemical stability for several thousand turnovers, which is often an exclusive feature of heterogeneous materials granted however by nanometric metal aggregates at least. Although implementation of smart methods for $\mathrm{M}_{3}{ }^{+}$recovery are still an open issue, we hope that present study will witness the potential of subnanometric low-nuclearity metal species in catalysis.

\section{ASSOCIATED CONTENT}

Supporting Information. The following files are available free of charge. Experimental procedures and details, synthesis of complexes, substrates and catalytic reactions, single crystal X-Ray data and cif files, copies of all NMR spectra (PDF).

\section{AUTHOR INFORMATION}

\section{Corresponding Author}

*E-mail: giovanni.maestri@unipr.it

*E-mail: max.malacria@,cnrs.fr

\section{Author Contributions}

\$These authors contributed equally 


\section{ACKNOWLEDGMENT}

We thank MIUR, UniPR, UPCM and CNRS for funding. Research on metal aromaticity is funded through SIR Project “AROMA-TriP” (Grant No.: RBSI14NKFL, GM) and FIL Project "RADICAT" (GM).

\section{REFERENCES}

(1) Boldyrev, A. I.; Wang, L.-S. All-Metal Aromaticity and Antiaromaticity. Chem. Rev. 2005, $105,3716-3757$.

(2) Tsipis, C. A. DFT study of "all-metal" aromatic compounds. Coord. Chem. Rev. 2005, 249, 2740-2762.

(3) Jena, P.; Castleman, A. W. Clusters: A bridge across the disciplines of physics and chemistry, PNAS 2006, 103, 10560-10569.

(4) Li, X.-W.; Pennington, W. T.; Robinson G. H. Metallic System with Aromatic Character. Synthesis and Molecular Structure of $\mathrm{Na}_{2}\left[\left[\left(2,4,6-\mathrm{Me}_{3} \mathrm{C}_{6} \mathrm{H}_{2}\right)_{2} \mathrm{C}_{6} \mathrm{H}_{3}\right] \mathrm{Ga}\right]_{3}$ The First Cyclogallane. J. Am. Chem. Soc. 1995, 117, 7578-7579.

(5) Robilotto, T. J.; Bacsa, J.; Gray, T. B.; Sadighi, J. P. Synthesis of a Trigold Monocation: An Isolobal Analogue of [H $\mathrm{H}_{3}$. Angew. Chem. Int. Ed. 2012, 51, 12077-12080.

(6) Freitag, K.; Gemel, C.; Jerabek, P.; Oppel, M. I.; Seidel, R. W.; Frenking, G.; Banh, H.; Dilchert, K.; Fischer, R. A. The $\sigma$-Aromatic Clusters $\left[\mathrm{Zn}_{3}\right]^{+}$and $\left[\mathrm{Zn}_{2} \mathrm{Cu}\right]$ : Embryonic Brass. Angew. Chem. Int. Ed. 2015, 54, 4370-4374. 
(7) Fu, F.; Xiang, J.; Cheng, H.; Cheng, L.; Chong, H.; Wang, S.; Li, P.; Wei, S.; Zhu, M.; Li, Y. A Robust and Efficient $\mathrm{Pd}_{3}$ Cluster Catalyst for the Suzuki Reaction and Its Odd Mechanism. ACS Catal. 2017, 7, 1860-1867.

(8) Mercero, J. M.; Boldyrev, A. I.; Merino, G.; Ugalde, J. M. Recent developments and future prospects of all-metal aromatic compounds. Chem. Soc. Rev. 2015, 44, 6519-6534.

(9) Hoffmann, R. The Many Guises of Aromaticity. Am. Sci. 2015, 103, 18-22.

(10) Wang, Y.; Deyris, P.A.; Cañeque, T.; Blanchard, F.; Li, Y.; Bigi, F.; Maggi, R.; Blanchard, S.; Maestri, G.; Malacria, M. A Simple Synthesis of Triangular All-Metal Aromatics Allowing Access to Isolobal All-Metal Heteroaromatics. Chem. Eur. J. 2015, 21, 12271-12274.

(11) Blanchard, S.; Fensterbank, L.; Gontard, G.; Lacôte, E.; Maestri, G.; Malacria, M. Synthesis of Triangular Tripalladium Cations as Noble-Metal Analogues of the Cyclopropenyl Cation. Angew. Chem. Int. Ed. 2014, 53, 1987-1991.

(12) Maestri, G.; Larraufie, M.-H.; Ollivier, C.; Malacria, M.; Fensterbank, L.; Lacôte, E. Rearrangements of N-Acyl Isothioureas. Alternate Access to Acylguanidines from Cyanamides. Org. Lett. 2012, 14, 5538-5541.

(13) Deyris, P.-A.; Cañeque, T.; Wang, Y.; Retailleau, P.; Bigi, F.; Maggi, R.; Maestri, G.; Malacria, M. Catalytic Semireduction of Internal Alkynes with All-Metal Aromatic Complexes. ChemCatChem 2015, 7, 3266-3269.

(14) Gladiali, S.; Alberico, E., Asymmetric transfer hydrogenation: chiral ligands and applications. Chem. Soc. Rev. 2006, 35, 226-236. 
(15) Samec, J. S. M.; Backvall, J. E.; Andersson, P. G.; Brandt, P., Mechanistic aspects of transition metal-catalyzed hydrogen transfer reactions. Chem. Soc. Rev. 2006, 35, 237-248.

(16) Blaser, H. U.; Malan, C.; Pugin, B.; Spindler, F.; Steiner, H.; Studer, M., Selective hydrogenation for fine chemicals: Recent trends and new developments. Adv. Synth. Catal. 2003, $345,103-151$.

(17) Noyori, R.; Hashiguchi, S., Asymmetric transfer hydrogenation catalyzed by chiral ruthenium complexes. Acc. Chem. Res. 1997, 30, 97-102.

(18) Li, G.; Jin, R. C., Gold Nanocluster-Catalyzed Semihydrogenation: A Unique Activation Pathway for Terminal Alkynes. J. Am. Chem. Soc. 2014, 136, 11347-11354.

(19) Radkowski, K.; Sundararaju, B.; Furstner, A., A Functional-Group-Tolerant Catalytic trans Hydrogenation of Alkynes. Angew. Chem. Int. Ed. 2013, 52, 355-360.

(20) Hauwert, P.; Boerleider, R.; Warsink, S.; Weigand, J. J.; Elsevier, C. J., Mechanism of Pd(NHC)-Catalyzed Transfer Hydrogenation of Alkynes. J. Am. Chem. Soc. 2010, 132, 1690016910.

(21) Hauwert, P.; Maestri, G.; Sprengers, J. W.; Catellani, M.; Elsevier, C. J. Transfer Semihydrogenation of Alkynes Catalyzed by a Zero-ValentPalladium N-Heterocyclic Carbene Complex. Angew. Chem. Int. Ed. 2008, 47, 3223-3226.

(22) Tokmic, K.; Fout, A. R. Alkyne Semihydrogenation with a Well-Defined Nonclassical CoH-2 Catalyst: A H-2 Spin on Isomerization and E-Selectivity. J. Am. Chem. Soc., 2016, 138, $13700-13705$. 
(23) Karunananda, M.K.; Mankad, N.P. E-Selective Semi-Hydrogenation of Alkynes by Heterobimetallic Catalysis. J. Am. Chem. Soc., 2015, 137, 14598-14601.

(24) Reddy, A.S.; Swamy, K.C.K. Ethanol as a Hydrogenating Agent: Palladium-Catalyzed Stereoselective Hydrogenation of Ynamides To Give Enamides. Angew. Chem. Int. Ed., 2017, $56,6984-6988$.

(25) Fu, S.M.; Chen, N.Y.; Liu, X.F.; Shao, Z.H.; Luo, S.P.; Liu, Q. Ligand-Controlled CobaltCatalyzed Transfer Hydrogenation of Alkynes: Stereodivergent Synthesis of Z- and E-Alkenes. J. Am. Chem. Soc., 2016, 138, 8588-8594.

(26) Yan, M.; Jin, T.; Ishikawa, Y.; Minato, T.; Fujita, T.; Chen, L. Y.; Bao, M.; Asao, N.; Chen, M. W.; Yamamoto, Y., Nanoporous Gold Catalyst for Highly Selective Semihydrogenation of Alkynes: Remarkable Effect of Amine Additives. J. Am. Chem. Soc. 2012, 134, 17536-17542.

(27) Polshettiwar, V.; Baruwati, B.; Varma, R. S., Nanoparticle-supported and magnetically recoverable nickel catalyst: a robust and economic hydrogenation and transfer hydrogenation protocol. Green Chem. 2009, 11, 127-131.

(28) Fedorov, A.; Liu, H.-J.; Lo, H.-K.; Copéret, C. Silica-Supported Cu Nanoparticle Catalysts for Alkyne Semihydrogenation: Effect of Ligands on Rates and Selectivity. J. Am. Chem. Soc. 2016, 138, 16502-16507.

(29) Masing, F.; Nusse, H.; Klingauf, J.; Studer, A. Light Mediated Preparation of Palladium Nanoparticles as Catalysts for Alkyne cis-Semihydrogenation. Org. Lett. 2017, 19, 2658-2661. 
(30) Chen, F.; Kreyenschulte, C.; Radnik, J.; Lund, H.; Surkus, A.E.; Junge, K.; Beller, M. Selective Semihydrogenation of Alkynes with N-Graphitic-Modified Cobalt Nanoparticles Supported on Silica. ACS Catalysis, 2017, 7, 15226-1532.

(31) Monfredini, A.; Santacroce, V.; Deyris, P.-A.; Maggi, R.; Bigi, F.; Maestri, G.; Malacria, M. Boosting catalyst activity in cis-selective semi-reduction of internal alkynes by tailoring the assembly of all-metal aromatic tri-palladium complexes. Dalton Trans. 2016, 45, 15786-15790.

(32) Padilla, E. M.; Golen, J. A.; Richmann, P. N.; Jensen, C. M. Effects of sulphur substituents on the geometries of dipalladium $\mu$-thiolato complexes: Crystal structures of $\mathrm{Pd}_{2} \mathrm{Cl}_{2}(\mu-\mathrm{Cl})(\mu$ $\mathrm{SR})\left(\mathrm{PMe}_{3}\right) 2(\mathrm{R}=\mathrm{Me}, \mathrm{t}-\mathrm{Bu}$ and $\mathrm{Ph})$ and $\mathrm{Pd}_{2} \mathrm{Cl}_{2}(\mu-\mathrm{SPh})_{2}\left(\mathrm{PEt}_{3}\right)_{2}$. Polyhedron 1991, 10, 13431352.

(33) Yamamoto, J. H.; Yap, G. P. A.; Jensen, C. M. Ring-Opening and Insertion of a Cyclic Thioether into a Palladium-Chlorine Bond. J. Am. Chem. Soc. 1991, 113, 5060-5061.

(34) Jain, V. K.; Patel, R. P.; Muralidharan, K. V.; Bohra, R. Dinuclear palladium (II) complexes with bridging mercapto group : X-ray crystal structure of a chloro/mercapto bridged dimer. Polyhedron 1989, 8, 2151-2155.

(35) Manolikakes, G.; Knochel, P. Radical Catalysis of Kumada Cross-Coupling Reactions Using Functionalized Grignard Reagents. Angew. Chem. Int. Ed. 2009, 48, 205-209.

(36) Maestri, G.; Malacria M.; Derat, E. Radical $\operatorname{Pd}(\mathrm{III}) / \mathrm{Pd}(\mathrm{I})$ reductive elimination in palladium sequences. Chem. Commun. 2013, 49, 10424-10426. 
(37) Boschi, T.; Crociani, B.; Toniolo, L.; Bellucco, U. Polynuclear Complexes of Palladium(II) with Halogen and Sulfur Bridges. Inorg. Chem. 1970, 9, 532-537.

(38) Ananikov, V. P.; Beletskaya, I. P. Toward the Ideal Catalyst: From Atomic Centers to a “Cocktail” of Catalysts. Organometallics, 2012, 31, 1595-1604.

(39) Crabtree, R. H. Resolving Heterogeneity Problems and Impurity Artifacts in Operationally Homogeneous Transition Metal Catalysts. Chem. Rev., 2012, 112, 1536-1554.

(40) Drost, R. M.; Rosar, V.; Dalla Marta, S.; Lutz, M.; Demitri, N.; Milani, B.; de Bruin, B.; Elsevier, C. J. Pd-Catalyzed Z-Selective Semihydrogenation of Alkynes: Determining the Type of Active Species. Chem CatChem, 2015, 7, 2095-2107.

(41) Gant, T. G. Using Deuterium in Drug Discovery: Leaving the Label in the Drug. J. Med. Chem. 2014, 57, 3595-3611.

(42) Cañeque, T.; Truscott, F. M.; Rodriguez, R.; Maestri, G.; Malacria, M. Electrophilic activation of allenenes and allenynes: analogies and differences between Bronsted and Lewis acid activation. Chem. Soc. Rev. 2014, 43, 2916-2926.

(43) Fensterbank, L.; Malacria, M. Molecular Complexity from Polyunsaturated Substrates: The Gold Catalysis Approach. Acc. Chem. Res. 2014, 47, 953-965.

(44) Fürstner, A.; Davies, P. W. Catalytic Carbophylic Activation: Catalysis by Platinum and Gold $\pi$ Acids. Angew. Chem. Int. Ed. 2007, 46, 3410-3449.

(45) Guo, H.; Zheng, Z.; Yu, F.; Ma, S.; Holuigue, A.; Tromp, D. S.; Elsevier, C. J.; Yu, Y. [Pd(Ar-BIAN)(alkene)]-Catalyzed Highly Chemo-, Regio-, and Stereoselective 
Semihydrogenation of 1,2-Allenyl Phosphonates and Related Compounds. Angew. Chem. Int. Ed. 2006, 45, 4997-5000.

(46) Dunn, P. J., The importance of Green Chemistry in Process Research and Development. Chem. Soc. Rev. 2012, 41, 1452-1461.

(47) Sheldon, R. A., Fundamentals of green chemistry: efficiency in reaction design. Chem. Soc. Rev. 2012, 41, 1437-1451.

(48) Sheldon, R. A., E factors, green chemistry and catalysis: an odyssey. Chem. Commun. 2008, $44,3352-3365$.

(49) Horvath, I. T.; Anastas, P. T., Innovations and green chemistry. Chem. Rev. 2007, 107, 2169-2173.

(50) Anastas, P. T.; Kirchhoff, M. M., Origins, current status, and future challenges of green chemistry. Acc. Chem. Res. 2002, 35, 686-694.

(51) Trost, B. M., Atom Economy—A Challenge for Organic Synthesis: Homogeneous Catalysis Leads the Way. Angew. Chem. Int. Ed. 1995, 34, 259-281.

(52) Unreacted triethylammonium formate and trimethylamine could be in principle recovered too at the end of the reaction via distillation, allowing one to further shrink green parameters. (53) To prevent overheating of large-scale reaction, neutralization of formic acid with trimethylamine can be carried out in advance using an ice bath and the resulting solution can be then stored and later syringed to the reaction flask. Repeating model experiments, this alternative did not impact on the reaction outcome. 
For table of contents use only graphics:

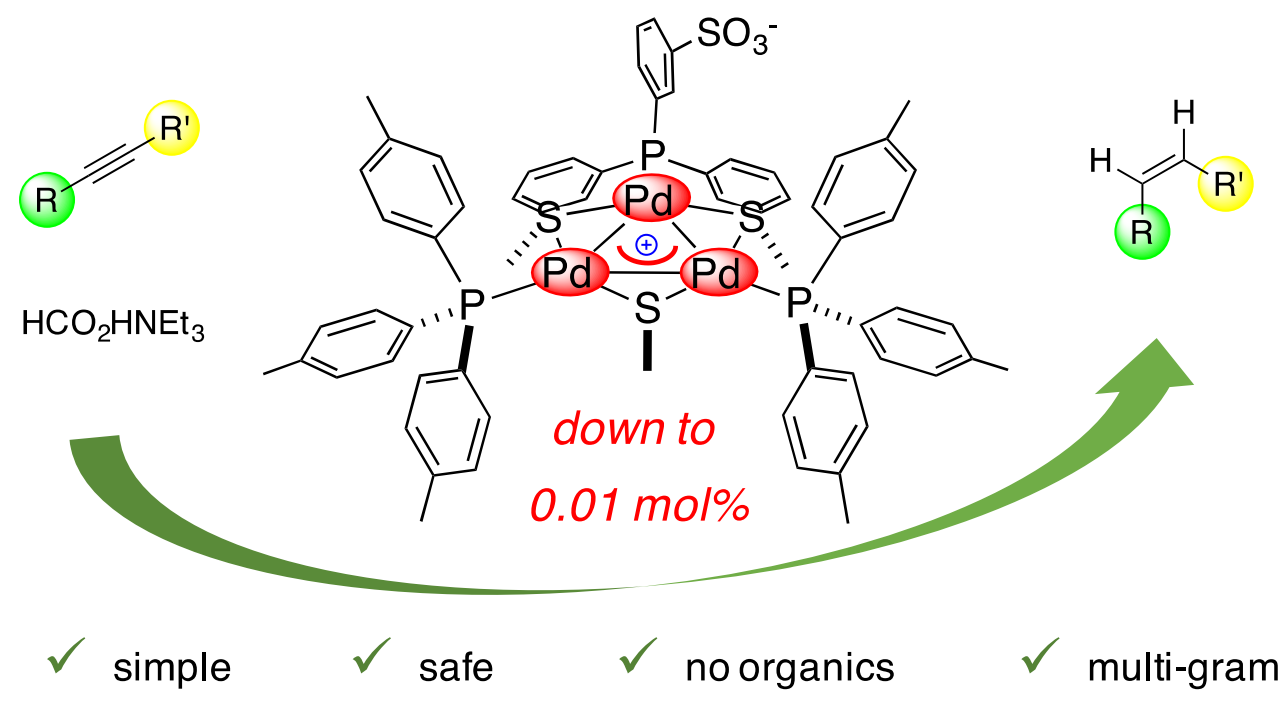

Synopsis: The tailor-made assembly of prototypical sub-nanometric palladium surfaces enables the smooth conversion of internal alkynes to cis-alkenes without any additional organics. 